\title{
Hyperbolic memory discounting and the political business cycle
}

\author{
T. Scott Findley* \\ Department of Economics and Finance, Jon M. Huntsman School of Business, \\ Utah State University, 3565 Old Main Hill, Logan, UT 84322-3565, USA
}

June 10, 2015

\begin{abstract}
The vintage political business cycle framework of Nordhaus (1975) represents the idea that the macroeconomic business cycle is manipulated opportunistically by an incumbent government to achieve re-election. A key assumption in this prototypical framework is that voters discount their memories about unemployment and inflation at a constant rate. Yet starting with Ebbinghaus (1885) and Jost (1897), a large body of research in psychology documents an empirical regularity that has come to be known as Jost's Second Law of Forgetting - individuals discount recent memories at a higher rate compared to the rate at which they discount older memories. I find that incorporating this insight from psychology (i.e., hyperbolic memory discounting) into the benchmark framework moderates the amplitude of the predicted political business cycle.
\end{abstract}

JEL classification: D03; D72

Keywords: Hyperbolic memory discounting; Jost's Second Law of Forgetting; Political business cycle; Inflation; Unemployment

*Tel.: +1-435-797-2371; Fax: +1-435-797-2701; E-mail address: tscott.findley@usu.edu 
Given two associations [memories] of the same strength, but of different ages, the older falls off less rapidly in a given length of time.

\section{Jost's Second Law of Forgetting}

Adolf Jost (1897)

Zeitschrift fuer Psychologie und Physiologie der Sinnesorgane

As translated and reported in Hovland (1951, p.649).

\section{Introduction}

Economists and political scientists have long been interested in studying and characterizing the interdependence of political and macroeconomic outcomes. Indeed, the idea that recessions and economic expansions might be politically induced was suggested by Kalecki (1943). However, it was the study of Nordhaus (1975) that was the first to model and mathematically depict an incumbent government that influences macroeconomic outcomes so that re-election can be achieved. The main prediction of this vintage framework is that recessions and economic expansions cycle around elections. More specifically, an incumbent government pursues policies to keep inflation low at the sacrifice of high unemployment during the early part of an electoral term. As time progresses during the term in office, inflationary policies are implemented so that the unemployment rate falls to acceptable levels before the pending date of re-election. This process repeats itself when the newly re-elected incumbent implements contractionary policies to keep inflation in check, resulting in high unemployment rates once again. ${ }^{1}$ The reason why these outcomes are pursued is because the incumbent government faces retrospective voters who discount their memories about past macroeconomic outcomes, such that high unemployment and low inflation are viewed by voters at election date as being much more costly if they were experienced in the recent past relative to the distant past. ${ }^{2}$

Due to the provocative prediction that opportunistic governments might be responsible for instigating economic fluctuations, the study of Nordhaus (1975) triggered a large ongoing effort to examine the assumptions of and/or to test the predictions of this prototypical framework. ${ }^{3}$

\footnotetext{
${ }^{1}$ This framework is agnostic about the channel through which the business cycle is manipulated, meaning that the incumbent could just as well be using fiscal/budget policy as monetary policy to induce the business cycle. Indeed, the control and state variables in the model are the unemployment and inflation rates respectively, without any background assumption regarding the source of policy. The incumbent is constrained by a short-run tradeoff between inflation and unemployment, and it is well-known that expansions or contractions in either monetary or fiscal/budget policy can lead to movements along a short-run Phillips Curve as long as expectations do not adjust immediately.

${ }^{2}$ Fiorina (1981) provides an in-depth discussion of the underlying mechanisms of retrospective voting.

${ }^{3}$ See Snowdon (1997) for a survey.
} 
Several of the assumptions in the model have been considered questionable at some point in time or another since it was published, yet subsequent research appears to be finding empirical support for many of these assumptions. ${ }^{4}$ Nevertheless, one feature that has not been examined very thoroughly in this sizable literature is the role of memory discounting. A key assumption in the vintage framework is that voters discount their memories exponentially about the pain from unemployment and inflation. Now at first glance it might appear obvious and trivial that an opportunistic incumbent will have more reason to manipulate the business cycle if voters remember less and less about the past. However, the assumption of exponential memory discounting is tenuous regardless of the specific magnitude of memory discounting, given that a long-standing body of research in psychology concludes that individuals discount their memories in a hyperbolic fashion, meaning that individuals discount recent memories at a higher rate compared to the rate at which they discount older memories. Indeed, beginning with the findings of Ebbinghaus (1885) that were extended by Jost (1897) and many others since, the behavioral phenomenon of hyperbolic memory discounting has been widely documented and has come to be recognized as Jost's Second Law of Forgetting in the field of psychology (e.g., Wixted and Ebbesen 1991; Rubin and Wenzel 1996; Alin 1997; Wixted 2004; Yi, Gatchalian, and Bickel 2006; Rachlin 2006; Brown, Neath, and Chater 2007; Yi, Landes, and Bickel 2009; Averell and Heathcote 2011). ${ }^{5}$

This paper has a very targeted focus - to demonstrate how the findings in psychology on hyperbolic memory discounting can affect the predictions of the vintage political business cycle model. ${ }^{6}$ Now one might conjecture a priori that an opportunistic incumbent will have a

\footnotetext{
${ }^{4}$ For example, the idea that people could be backward-looking when voting was deemed unpalatable from the perspective of the 'rational expectations' paradigm. However, much of the latest research in political science and psychology suggests that retrospective voting behavior is much more empirically plausible than previously supposed (e.g., Francis, Kenny, Morton, and Schmidt 1994; Lanoue 1994; Williams 1994; Kiewiet and Udell 1998; Anderson 2000; Nadeau and Lewis-Beck 2001; Söderlund 2008; Campbell, Dettrey, and Yin 2010). Mueller (2003) reports that retrospective voting over economic outcomes is a robust empirical phenomenon. See Murakami (2008) for a survey of the evidence on the pervasiveness of retrospective voting in US presidential elections, US congressional elections, US gubernatorial elections, and elections in other countries.

${ }^{5}$ Although the specific functional form often differs from one psychology study to the next (e.g., 'power-law', 'exponential-power', 'hyperbolic-log', 'hyperbolic-power'), what I am characterizing as 'hyperbolic discounting' is the entire class of memory discount functions that exhibit a declining discount rate in the retrospective delay. More precisely, given a memory discount function in general form $M(x)$ for a delay of $x$, the discount rate is the proportional rate of decline in the function, $m(x) \equiv-d \ln [M(x)] / d x$, and I am labeling any function as 'hyperbolic' if it exhibits the property of $d m(x) / d x<0$, which reflects Jost's Second Law of Forgetting.

${ }^{6}$ It would also be of interest to examine the impact of hyperbolic discounting on partisan political business cycles, rational political business cycles, and political budget cycles. Yet, in this paper I focus on the vintage political business cycle framework of Nordhaus (1975) because its setup, motivating assumptions, and baseline predictions are generally well-known. And in the set of possible political business cycle models that could be re-visited, it is very natural to start with the first one, which is still being re-examined and tested (e.g., García-Sanchez, Mordán, and Cuadrado-Ballesteros 2014; Vásquez-Ruíz, Rivas, and Díaz 2014; Basak, Ghosh, and Mukherjee 2015).
} 
stronger incentive to manipulate the business cycle if voters forget the recent past relatively more quickly, as is the case with hyperbolic discounting compared to exponential discounting. However, hyperbolic memory discounting also implies that voters forget the distant past at a relatively lower rate compared to exponential discounting. I find that the way in which voters discount the past is of first-order importance to the predictions of the model. More specifically, I find both analytically and numerically that the amplitude of the predicted business cycle is moderated in both the inflation and the unemployment dimensions, relative to the case of exponential discounting. For example, in basic numerical exercises the predicted amplitude of the unemployment rate ranges between 2.7 and 2.9 percentage points for the entire range of discounting magnitudes (low, moderate, high) under the best-fitting hyperbolic functional form. This stands in sharp contrast to the predicted peak-to-trough amplitudes of the unemployment rate for the same range of discounting magnitudes under exponential discounting: the amplitude is around 7 percentage points (cycles between 11 percent and 4 percent every four years) at low discounting magnitudes, 26 percentage points (cycles between 30 percent and 4 percent) at moderate magnitudes, and 91 percentage points (cycles between 95 percent and 4 percent) at high magnitudes. ${ }^{7}$ Conditional on the form of the penalty-vote function used in the benchmark framework, these predicted outcomes result from the fact that it is not nearly as easy for an incumbent government to exploit retrospective voters whose recent memories decay quickly but whose older memories decay slowly. Alternatively stated, an opportunistic incumbent cannot get away with nearly as much manipulation during the early part of an electoral term if voters remember relatively more about economic outcomes in that early part of the term under hyperbolic memory discounting. ${ }^{8}$

In the context of the existing literature on opportunistic political business cycles, these findings could be interpreted in some different ways. Although one could justifiably view the numerical predictions of the vintage framework with a heavy dose of skepticism given its stylized assumptions, one interpretation is that this framework might have more to offer in providing some basic insight into macroeconomic fluctuations than has been supposed previously. This is

\footnotetext{
${ }^{7}$ Nordhaus (1975) assumed that the exponential memory discount rate was 3 percent per annum in the original study. Yet, some subsequent empirical research finds that the exponential discount rates of voters range between 50 and 144 percent per annum (e.g., Hibbs and Vasilatos 1981, 1982; Hibbs, Rivers, and Vasilatos 1982; Chappell 1983; Hibbs 1987).

${ }^{8}$ Beginning with findings by Herrnstein (1961), Rachlin and Green (1972), Ainslie (1975) and many others, a parallel body of research independently finds evidence of hyperbolic discounting over future delays. Such forward-looking hyperbolic discounting has been used to represent various phenomena such as impulsivity, selfcontrol failure, and procrastination, since it generates time-inconsistent decision making (Strotz 1956; Laibson 1997, 1998). Now it is certainly the case that voters are time-inconsistent in their valuation of past inflation and unemployment in the current model with hyperbolic memory discounting. Yet, all that really matters to the incumbent government's decision making is how voters feel about past unemployment and inflation from the perspective of the election date when they actually vote. As such, decision making by the incumbent is time-consistent in the model.
} 
due to the fact that the model generates numerical predictions that are grossly counterfactual when estimates of the discount rate are combined with the assumption of exponential memory discounting, whereas replacing exponential discounting with hyperbolic memory discounting brings the simple numerical predictions of the model in line with the changes in unemployment rates and inflation rates that are typically measured in data. ${ }^{9,10}$ Yet there is an alternative way to interpret these findings: the presence of hyperbolic memory discounting might account for the mixed body of empirical evidence as to whether opportunistic political business cycles even exist in the first place. ${ }^{11}$ This is due to the fact that hyperbolic memory discounting leads to predicted political business cycles that are drastically less pronounced, relative to what is predicted under the original assumption of exponential discounting.

\section{Vintage model with a general discount function}

\subsection{Optimization problem and solutions}

Time is continuous and indexed by $t$. From the perspective of being newly elected (or newly re-elected), it is assumed that at $t=0$ a government desires to be re-elected at the next future election date $t=E$. As such, the government selects the time path of the unemployment rate, $u(t)$, and the actual inflation rate, $\pi(t)$, in order to maximize its vote function. Given an instantaneous payoff (penalty) vote function $\nu(u, \pi)$ with $\partial \nu / \partial u<0$ and $\partial \nu / \partial \pi<0$, this problem can be stated formally as

$$
\max \quad V=\int_{0}^{E} \nu(u(t), \pi(t)) M(E-t) d t,
$$

where $M(x)$ is a memory discount function in general form for a retrospective discounting delay of $x$ with $M(0)=1$ and $d M / d x<0$. The retrospective discount function governs how voters devalue memories about past pain from inflation and unemployment over the course of the incumbent government's term in office.

The incumbent government is constrained by an expectations-augmented Phillips Curve

\footnotetext{
${ }^{9}$ For example, the US has experienced eleven recessions since 1948 in which the peak-to-trough (or troughto-peak) amplitude of the unemployment rate averaged 3.4 percentage points, with a maximum amplitude of 5.8 percentage points that accompanied the 1981-1982 recession.

${ }^{10}$ Note that this study is not intended to quantitatively match all of the moments in the data on business cycles. Instead, this study examines how basic numerical predictions line up with just one very stylized fact (amplitude) about business cycles, in order to better understand the role of memory discounting.

${ }^{11}$ Mueller (2003) reports that the Nordhaus (1975) framework is the only one that has been extensively tested by researchers in a consistent manner, and that this body of research is sizable with roughly equal amounts of evidence for and against the existence of opportunistically induced political business cycles.
} 
relationship

$$
\pi(t)=\varphi(u(t))+\psi \varepsilon(t) .
$$

The parameter $\psi \in(0,1]$ is the proportion by which expected inflation materializes into actual inflation. ${ }^{12}$ Note that $d \varphi / d u<0$ and also note that the expected rate of inflation $\varepsilon(t)$ evolves adaptively in the vintage framework

$$
\begin{gathered}
\frac{d \varepsilon(t)}{d t}=\gamma[\pi(t)-\varepsilon(t)], \text { for } t \in[0, E], \\
\varepsilon(0) \text { given, } \\
\varepsilon(E) \text { free. }
\end{gathered}
$$

Equation (3) represents the idea that revisions to the expected inflation rate are proportional to the forecast error by $\gamma>0$. Therefore, $\gamma$ can be considered the speed of adaptation or adjustment in inflation expectations. ${ }^{13,14}$

As in the original framework, the following functional forms are used to solve the model explicitly

$$
\begin{gathered}
\nu(u, \pi)=-u(t)^{2}-\theta \pi(t), \\
\varphi(u)=\alpha-\zeta u(t),
\end{gathered}
$$

where $\theta>0$ governs the intensity with which inflation enters the penalty function and where $\zeta>0$ is the slope of and $\alpha>0$ affects the intercepts of the short-run and long-run Phillips Curves. Note that when $\varepsilon=\pi$ given $\psi=1$, the long-run natural rate of unemployment is identified. This is equal to $\alpha / \zeta$ for the functional forms specified in (2) and (7). Note also that $\partial \nu / \partial u<0$ and $\partial \nu / \partial \pi<0$ given (6). With the appropriate substitutions, the Hamiltonian is

\footnotetext{
${ }^{12}$ The parameter $\psi$ determines whether or not a tradeoff exists between inflation and unemployment in the long run, wherein $d \varepsilon / d t=0$ and $\varepsilon=\pi$ by (3). In this case the Phillips Curve becomes $\pi=(1-\psi)^{-1} \times \varphi(u)$ with slope $(1-\psi)^{-1} \times d \varphi / d u$. The Phillips Curve is vertical in the long run if $\psi=1$. But if $\psi<1$, then a tradeoff exists in the long run given that $d \varphi / d u<0$.

${ }^{13}$ Burmeister and Turnovsky (1976) outline some caveats concerning the specification of adaptive expectations in continuous-time settings.

${ }^{14}$ The proposition of adaptive inflation expectations was dismissed for the most part with the 'rational expectations' revolution. However, recent research suggests that adaptive expectations about inflation might be much more tenable in many settings than the idea that inflation expectations are formed rationally by voters, especially when the true data generating process is unknown (e.g., Suzuki 1991; Haller and Norpoth 1994; Hey 1994; Sargent 1999; Evans and Honkapohja 2001; Agliari, Chiarella, and Gardini 2006). Muth (1960) demonstrated that adaptive expectations and rational expectations are the same if the data generating process follows a random walk. See Shepherd (2012) and Sorge (2013) for a generalization in which adaptive expectations can be considered rational since it can produce minimized forecast errors.
} 
written as

$$
\mathcal{H}(t)=\left[-u(t)^{2}+\theta \zeta u(t)-\alpha \theta-\theta \psi \varepsilon(t)\right] M(E-t)+\lambda(t) \gamma[\alpha-\zeta u(t)-(1-\psi) \varepsilon(t)]
$$

Assuming that $u(t) \in[0,1]$ for all $t \in[0, E]$, application of the Maximum Principle for finitehorizon, free-endpoint control problems yields a system of optimality conditions

$$
\begin{gathered}
\frac{\partial \mathcal{H}(t)}{\partial u(t)}=[-2 u(t)+\theta \zeta] M(E-t)-\gamma \zeta \lambda(t) \stackrel{\text { set }}{=} 0, \\
\frac{\partial \mathcal{H}(t)}{\partial \varepsilon(t)}=-\theta \psi M(E-t)-(1-\psi) \gamma \lambda(t) \stackrel{\text { set }}{=}-\frac{d \lambda(t)}{d t}, \\
\frac{\partial \mathcal{H}(t)}{\partial \lambda(t)}=\gamma[\alpha-\zeta u(t)-(1-\psi) \varepsilon(t)] \stackrel{\text { set }}{=} \frac{d \varepsilon(t)}{d t}, \\
\varepsilon(0) \text { given, } \\
\lambda(E)=0,
\end{gathered}
$$

where $u(t)$ is the control variable, $\varepsilon(t)$ is the state variable, and $\lambda(t)$ is a multiplier function. Solving this system of equations yields the optimal path of the unemployment rate and the inflation rate

$$
\begin{aligned}
u^{*}(t)= & \frac{\theta \zeta}{2}\left[1+\frac{\gamma \psi \exp [(1-\psi) \gamma t]}{M(E-t)} \int_{t}^{E} M(E-s) \exp [-(1-\psi) \gamma s] d s\right], \text { for } t \in[0, E], \\
\pi^{*}(t)= & \alpha-\frac{\theta \zeta^{2}}{2}\left[1+\frac{\gamma \psi \exp [(1-\psi) \gamma t]}{M(E-t)} \int_{t}^{E} M(E-s) \exp [-(1-\psi) \gamma s] d s\right] \\
& +\psi \exp [-(1-\psi) \gamma t]\left[\varepsilon(0)+\int_{0}^{t}\left[\alpha \gamma-\gamma \zeta u^{*}(j)\right] \exp [(1-\psi) \gamma j] d j\right], \text { for } t \in[0, E],
\end{aligned}
$$

where $s$ and $j$ are dummy variables of integration. Following equations (14) and (15) maximizes the hope of re-election for an opportunistic incumbent government. Due to the extensive expression of (15), the optimal path for the inflation rate can be approximated alternatively. First, approximate the actual path of the expected inflation rate, $\varepsilon(t)$, by transforming equation (3) into differential form such that exact or true changes in the expected inflation rate, $\Delta \varepsilon(t)$, will approximately follow

$$
d \varepsilon(t)=(\gamma[\pi(t)-\varepsilon(t)]) d t
$$

given a discrete change in time of $d t=\Delta t$ in advancing from one period during the term in office to the next. With $\varepsilon(0)$ given this implies that the path of the expected inflation rate will 
follow

$$
\begin{aligned}
\varepsilon(t+d t) & =\varepsilon(t)+\Delta \varepsilon(t) \\
& \approx \varepsilon(t)+d \varepsilon(t) \\
& =\varepsilon(t)+(\gamma[\pi(t)-\varepsilon(t)]) d t
\end{aligned}
$$

for all $t \in[0, E]$, remembering that the approximation becomes more precise as $d t \rightarrow 0$. Lastly, insert (14) and (17) into (2) to approximate (15).

\subsection{Memory discount functions and discount rates}

Until now the memory discount function has been left in general form, $M(x)$ for a retrospective discounting delay of $x$. I now entertain some alternative forms: the exponential function (that has already been widely used in the vintage political business cycle framework), and some hyperbolic memory discount functions. The exponential discount function is

$$
M_{e}(x)=\exp [-\rho x], \text { for } \rho \in \mathbb{R}^{+} .
$$

Research findings in the field of psychology suggest some prominent hyperbolic functional forms that all satisfy Jost's Second Law of Forgetting: the traditional or standard hyperbolic function, the hyperbolic-log function, and the hyperbolic-power function. These are respectively given as

$$
\begin{gathered}
M_{h}(x)=[1+\beta x]^{-1}, \text { for } \beta \in \mathbb{R}^{+}, \\
M_{l}(x)=[1+\mu \ln [1+x]]^{-1}, \text { for } \mu \in \mathbb{R}^{+}, \\
M_{p}(x)=\left[1+\eta x^{\sigma}\right]^{-1}, \text { for } \eta \in \mathbb{R}^{+}, \sigma \in(0,1] .
\end{gathered}
$$

These functions are some of the most commonly used forms that have provided goodness of fit to data generated by subjects in their abilities to retain information over time in experimental laboratory settings. ${ }^{15,16}$ The proportional rate of decline in a memory discount function is the memory discount rate,

$$
m(x) \equiv-d \ln [M(x)] / d x
$$

The exponential memory discount rate is $m_{e}(x)=\rho$ which violates Jost's Second Law of Forgetting on account that $d m_{e}(x) / d x=0$. The memory discount rates for the various hyperbolic forms are $m_{h}(x)=\beta /[1+\beta x]$ for the standard hyperbolic function, $m_{l}(x)=$

\footnotetext{
${ }^{15}$ See Rubin and Wenzel (1996) and Averell and Heathcote (2011) for an overview.

${ }^{16}$ Due to its additional parameter, the hyperbolic-power function typically provides the best fit to experimental data from among these functional forms.
} 
$\mu /[(1+x)(1+\mu \ln [1+x])]$ for the hyperbolic-log function, and $m_{p}(x)=\left[\eta \sigma x^{\sigma-1}\right] /\left[1+\eta x^{\sigma}\right]$ for the hyperbolic-power function. These alternative hyperbolic functions all satisfy Jost's Second Law of Forgetting since $d m_{i}(x) / d x<0$ with $i \in\{h, l, p\} .{ }^{17}$

A challenge exists when comparing how the predictions of a model change when different memory discount functions are used. Namely, alternative discount functions have different rates of decline (slope effects) in addition to potentially having different levels of overall discounting. As mentioned above, the idea that recent memories decay at a much higher rate than the rate at which older memories decay (Jost's Second Law of Forgetting) is tied to the fact that the memory discount rate decreases in the delay (i.e., $d m(x) / d x<0$ ) and is not directly related to the overall level of discounting. Given that the research objective is to study how the form of the memory discount function affects the predictions of the vintage political business cycle framework, it is imperative to control for differences in overall levels of memory discounting at moments of decision making, so that the slope effects of discounting can be properly identified.

For a given memory discount function, a theoretically neutral measure of the overall level of discounting is the area that is below a line at unity yet above the discount function (Myerson, Green, and Warusawitharana 2001; Myerson, Green, Hanson, Holt, and Estle 2003; Myerson and Green 2004). Following Caliendo and Findley (2014), this area can be mathematically defined as $\Phi(t) \equiv \int_{t}^{E}[1-M(E-s)] d s=E-t-A(t)$ from the perspective of any arbitrary $t \in[0, E]$ where $E-s$ is the retrospective delay and $A(t) \equiv \int_{t}^{E} M(E-s) d s$ is the area under the memory discount function. This represents the cumulative discounting of a flow of past memories over a retrospective horizon. Since the area under a discount function is inversely proportional to the overall level of discounted memories (i.e., $\partial \Phi(t) / \partial A(t)=-1$ ), controlling for differences in overall levels of memory discounting can be operationalized by equalizing the areas under different discount functions at the moment of decision making in the model $(t=0)$, meaning $A_{e}(0)=A_{i}(0)$ with $i \in\{h, l, p\}$.

I therefore discipline the parameters of the hyperbolic memory discount functions $(\beta, \mu$, and $\eta$ with $\sigma=0.33$ ) by numerically solving

$$
\min _{\{\beta, \mu, \eta\}}\left\{\sum_{i=h, l, p}\left(\int_{0}^{E} M_{e}(E-t) d t-\int_{0}^{E} M_{i}(E-t) d t\right)^{2}\right\},
$$

for a given value of the exponential discount rate, $\rho$. This procedure equalizes the areas under each of the four discount functions, thus controlling for differences in overall levels of discounted memories. What remains are the effects of how memories decay in the retrospective delay. I

\footnotetext{
${ }^{17}$ The restriction of $\sigma \in(0,1]$ is necessary and sufficient for the hyperbolic-power discount function to be consistent with Jost's Second Law of Forgetting. It should be noted that the hyperbolic-power function takes on the standard hyperbolic form if $\sigma=1$.
} 
assume $\rho=0.50, \rho=0.95$, and $\rho=1.35$ to depict 'low', 'moderate', and 'high' rates of memory discounting. These values all fall within the range of some empirical estimates for the rate at which voters exponentially discount their past memories about political and macroeconomic outcomes (e.g., Hibbs and Vasilatos 1981, 1982; Hibbs, Rivers, and Vasilatos 1982; Chappell 1983; Hibbs 1987). ${ }^{18,19}$ Parameterizing the alternative memory discount functions with (23) to control for differences in overall levels of discounting generates the following discount function parameters: (i) $\beta=0.86, \mu=1.52$, and $\eta=1.16$ if $\rho=0.50$, which is labeled the case of 'low discounting'; (ii) $\beta=2.23, \mu=3.68$, and $\eta=2.60$ if $\rho=0.95$, which is labeled the case of 'moderate discounting'; and, (iii) $\beta=3.77, \mu=5.98$, and $\eta=4.04$ if $\rho=1.35$, which is labeled the case of 'high discounting'. The memory discount functions for these three cases are depicted in Figure 1, Figure 5, and Figure 9, respectively. It is clear from these three figures that the areas under all four discount functions are the same, even though the functions have different proportional rates of decline.

\subsection{Some basic analytical findings}

Before turning to numerical exercises, here I provide some analytical insight into the effects of hyperbolic memory discounting on the predictions of the vintage political business cycle framework. First, it should be mentioned that in the case of exponential memory discounting Nordhaus (1975) documented $d u^{*}(t) / d t<0$ for $t \in[0, E)$. It is straightforward to show from (14) that this continues to hold for any specification of the memory discount function. Second, the unemployment rate that immediately precedes an election is denoted as

$$
\lim _{t \rightarrow E}\left\{u^{*}(t)\right\}=\frac{\theta \zeta}{2}
$$

This means that the predicted unemployment rate converges to the same value by the date of re-election regardless of the form of the memory discount function.

Lastly, the predicted unemployment rate under hyperbolic memory discounting is strictly lower than the unemployment rate under exponential discounting over the time interval $\left[0, \bar{t}_{i}\right]$ with $i \in\{h, l, p\}$, and it is also possible, perhaps even likely, that the unemployment rate is lower under hyperbolic memory discounting for some of the interval $\left(\bar{t}_{i}, E\right)$ with $i \in\{h, l, p\}$, where $\bar{t}_{i} \in(0, E)$ is the unique date at which each of the hyperbolic memory discount functions

\footnotetext{
${ }^{18}$ Estimates for the exponential memory discount rate of voters typically range between 50 and 144 percent per annum. However, Hibbs and Vasilatos (1982) also report that the discount rate might be as high as 4700 percent per annum for voters in the United Kingdom who are unskilled or semi-skilled workers.

${ }^{19}$ Fair (1978) reports that the memory discount rate of a typical voter is a very high number that might even approach infinity. This would suggest that voters might not be retrospective at all when voting. Yet despite this incredibly high estimate, Fair still asserts that voters do pay attention to economic outcomes within the year that immediately precedes an election.
} 
respectively intersect the exponential function only once (see Figure 1, Figure 5, and Figure $9)$. To demonstrate this analytically, I set $\psi=1$ for convenience which means that there is no long-run tradeoff between inflation and unemployment in the model (see Footnote 12). ${ }^{20}$ For the cases of exponential and hyperbolic memory discounting, (14) becomes

$$
\begin{gathered}
u_{e}^{*}(t)=\frac{\theta \zeta}{2}\left[1+\frac{\gamma}{M_{e}(E-t)} A_{e}(t)\right], \text { for } t \in[0, E], \\
u_{i}^{*}(t)=\frac{\theta \zeta}{2}\left[1+\frac{\gamma}{M_{i}(E-t)} A_{i}(t)\right], \text { for } t \in[0, E] \text { with } i \in\{h, l, p\},
\end{gathered}
$$

remembering that $A(t)$ is the area under a memory discount function. To isolate the slope effects from the alternative forms of memory discounting, the areas under each respective discount function need to be equalized at the moment of decision making, $A_{e}(0)=A_{i}(0)$ with $i \in\{h, l, p\}$. At $t=0,(25)$ and $(26)$ can therefore be written as

$$
\begin{gathered}
u_{e}^{*}(0)=\frac{\theta \zeta}{2}\left[1+\frac{\gamma}{M_{e}(E)} A_{e}(0)\right], \\
u_{i}^{*}(0)=\frac{\theta \zeta}{2}\left[1+\frac{\gamma}{M_{i}(E)} A_{i}(0)\right], \text { with } i \in\{h, l, p\},
\end{gathered}
$$

where it is clear to see that $u_{e}^{*}(0)>u_{i}^{*}(0)$, since $M_{e}(E)<M_{i}(E)$ with $i \in\{h, l, p\}$. Thus, $u_{e}^{*}(0)>u_{i}^{*}(0)$ and $u_{e}^{*}(E)=u_{i}^{*}(E)$ with $i \in\{h, l, p\}$ from (24). But how does hyperbolic memory discounting affect the unemployment rate over the interval $t \in(0, E)$ ?

It should be noted that if $A_{e}(0)=A_{i}(0)$ with $i \in\{h, l, p\}$ to perform a controlled comparison of discount functions, then it is the case mathematically that $A_{e}(t)>A_{i}(t)$ for all $t \in(0, E)$, recognizing that $A_{e}(t) \rightarrow 0$ and $A_{i}(t) \rightarrow 0$ with $i \in\{h, l, p\}$ as $t \rightarrow E$. This is an unambiguous force for the unemployment rate under hyperbolic discounting to be strictly less than the unemployment rate under exponential discounting for $t \in(0, E)$. Therefore, all that remains to be determined is the relative heights of the alternative discount functions, meaning is $M_{e}(E-t)$ greater than, equal to, or less than $M_{i}(E-t)$ with $i \in\{h, l, p\}$ over the interval $t \in(0, E)$ ?

On account that $A_{e}(0)=A_{i}(0)$ with $i \in\{h, l, p\}$ to perform a controlled comparison, there exists a unique date $\bar{t}_{i} \in(0, E)$ at which each one of the hyperbolic discount functions intersects the exponential discount function only once (again see Figure 1, Figure 5, and Figure 9). As such, $M_{e}\left(E-\bar{t}_{i}\right)=M_{i}\left(E-\bar{t}_{i}\right)$ with $i \in\{h, l, p\}$ at the unique date of intersection, $\bar{t}_{i} \in(0, E)$. Moreover, it follows that $M_{e}(E-t)<M_{i}(E-t)$ for $t \in\left[0, \bar{t}_{i}\right)$, and $M_{e}(E-t)>M_{i}(E-t)$ with $i \in\{h, l, p\}$ for all $t \in\left(\bar{t}_{i}, E\right)$. Therefore, it is unambiguously the case that $u_{e}^{*}(t)>u_{i}^{*}(t)$ with $i \in\{h, l, p\}$ for all $t \in\left[0, \bar{t}_{i}\right]$, since $M_{e}(E-t) \leq M_{i}(E-t)$ for $t \in\left[0, \bar{t}_{i}\right]$ reinforces

\footnotetext{
${ }^{20}$ Gordon (1997) provides an overview of the evidence that the long-run Phillips Curve is likely vertical.
} 
$A_{e}(t)>A_{i}(t)$ for $t \in(0, E)$. Whether or not $u_{e}^{*}(t)>u_{i}^{*}(t)$ for $t \in\left(\bar{t}_{i}, E\right)$ is a quantitative question since $M_{e}(E-t)>M_{i}(E-t)$ for $t \in\left(\bar{t}_{i}, E\right)$ is a counterforce on $A_{e}(t)>A_{i}(t)$ over the interval. In sum, the predicted unemployment rate under hyperbolic memory discounting will be unambiguously lower than the unemployment rate under exponential discounting during the first part of an electoral term, meaning for $t \in\left[0, \bar{t}_{i}\right]$. And it is also quantitatively possible, perhaps even likely, that the unemployment rate is lower under hyperbolic discounting for much of the interval $\left(\bar{t}_{i}, E\right)$ as well.

\section{$3 \quad$ Numerical exercises}

\subsection{Parameter values and calibration}

I set $E=4$ to reflect a term in office of four years. The speed of adjustment in inflation expectations is set to $\gamma=0.14$. This is lower than the value used in Nordhaus (1975) because higher values for $\gamma$ lead to predicted unemployment rates that exceed 100 percent (which invalidates the solutions to the optimal control problem) given the range of empirical estimates for the exponential discount rate. I normalize $\pi_{p}^{*}(0)=0.03$ by calibrating the initial condition on inflation expectations, $\varepsilon(0)$. However, this is an innocuous exercise since this only sets the level of the inflation rate for expositional purposes and it does not have any material affect on its amplitude. Following the analytical section above, the proportion by which expected inflation affects actual inflation is set to $\psi=1$. This means that the long-run Phillips Curve is vertical at the natural rate of unemployment in the model. Yet, this assumption also is innocuous since the findings are generally robust to a long-run Phillips Curve that is negatively sloped. ${ }^{21}$

Common estimates for the slope coefficient of the short-run Phillips Curve range between 0.3 to 0.9 (e.g., Staiger, Stock, and Watson 1997; King and Morley 2007; Lee and Nelson 2007). I entertain the midpoint on this range for the slope parameter: $\zeta=0.6$. As noted by (24), the unemployment rate that immediately precedes an election is $\theta \zeta / 2$. This is used to calibrate the unobservable parameter, $\theta$, given the above-mentioned midpoint value for the slope of the short-run Phillips Curve. The average unemployment rate in the month of October prior to presidential elections in the US since 1948 is around 4 percent. Using this target gives $\theta=0.133$ if $\zeta=0.6$. A value of $\alpha=0.03$ generates a natural rate of unemployment in the model that is equal to 5 percent given $\psi=1$ and given the numerical value of $\zeta=0.6$ outlined above. ${ }^{22}$

\subsection{Low discounting: Numerical examples and discussion}

\footnotetext{
${ }^{21}$ I find that the predicted inflation cycle can be eliminated and sometimes it can even be slightly inverted at parameterizations in which there is a long-run tradeoff between inflation and unemployment in the model.

${ }^{22}$ This value for the natural rate of unemployment is consistent with estimates for the US economy (Staiger, Stock, and Watson 1997; Salemi 1999; King and Morley 2007).
} 
Recall that (23) is used to select the parameters for each of the hyperbolic discount functions given a particular value of $\rho$. This controls for differences in total memories discounted across all of the alternative discount functions. For the case of $\rho=0.50$ labeled as 'low discounting', this procedure generates the following hyperbolic discount function parameters: $\beta=0.86$, $\mu=1.52$, and $\eta=1.16$ with $\sigma=0.33$. Recall that a value of $\rho=0.50$ is at the lower bound of empirical estimates (50 percent to 144 percent per annum) for the rate of exponential memory discounting over political-economic outcomes (e.g., Hibbs and Vasilatos 1981, 1982; Hibbs, Rivers, and Vasilatos 1982; Chappell 1983; Hibbs 1987). The alternative memory discount functions are each depicted in Figure 1 for this parameterization. It is straightforward to see that each of the hyperbolic memory discount functions have higher rates of decline over shorter retrospective delays (relative to the exponential discount function), yet lower rates of decline over longer retrospective delays.

The time paths of the unemployment rate and the inflation rate corresponding to each of the alternative memory discount functions are depicted in Figures 2 and 3 for the duration of one electoral term (i.e., $E=4$ ). As described in Nordhaus (1975), the cyclical fluctuations in the predicted unemployment rate and the predicted inflation rate are constructed in the model over the span of multiple electoral terms. As discussed in the analytical section above, the unemployment rate falls over the course of a term in office for each of the different cases of memory discounting. Moreover, the time paths of the unemployment rate all converge to 4 percent by the date of re-election, as also outlined above. Yet, there are several additional things to note from Figure 2. First, the model-generated natural rate of unemployment has been inserted as a benchmark of comparison. This suggests that the opportunistic incumbent government in the model pushes the economy above full employment by the date of re-election. Second, the average unemployment rate over the course of a term in office is 6.5 percent, 5.9 percent, 5.6 percent, and 5.3 percent for the exponential, standard hyperbolic, hyperbolic-log, and hyperbolic-power functions, respectively. All of these predicted averages are reasonably close to the average unemployment rate of 5.8 percent in the US since 1948. However, it is important to recall that these predicted averages actually follow from the calibration procedure (outlined above) in which a numerical value for the unobservable parameter $\theta$ is selected such that the pre-election unemployment rate is equal to 4 percent regardless of the form of the memory discount function. Other pre-election unemployment rates could have been targeted alternatively, which would lead to different predicted averages that could match the average unemployment rates in other economies.

Lastly, the peak-to-trough amplitude of the unemployment rate is 7.2 percentage points for the case of exponential discounting, while the amplitudes are 4.3 percentage points, 3.3 percentage points, and 2.7 percentage points for the standard hyperbolic, hyperbolic-log, and 
hyperbolic-power functions respectively. Since 1948 the US has experienced eleven recessions in which the peak-to-trough (or trough-to-peak) amplitude of the unemployment rate averaged 3.4 percentage points, with a maximum amplitude of 5.8 percentage points that accompanied the 1981-1982 recession. The predicted amplitude of 7.2 percentage points for the case of exponential discounting exceeds the largest amplitude ever experienced in the US since 1948, while the predicted amplitudes for the alternative cases of hyperbolic discounting are fairly close to the average amplitude and below the largest amplitude experienced over this time frame.

Figure 3 documents how the predicted inflation rate is affected by hyperbolic discounting. Given that the incumbent is constrained by a tradeoff between unemployment and inflation, the inflation rate rises over the duration of an electoral term given that the unemployment rate is falling. What is of interest in Figure 3 is the fact that the amplitude of the predicted inflation rate is moderated with a relative bias in the level of the inflation rate.

Figure 4 depicts the model-generated short-run Phillips Curves and the model-generated long-run Phillips Curve. At the beginning of an electoral term, the incumbent government starts at the most south-easterly point on a short-run Phillips Curve where the unemployment rate is relatively high but the inflation rate is relatively low. As time advances over the course of an electoral term, the economy travels up the short-run Phillips Curve in the north-westerly direction such that the unemployment rate is relatively low and the inflation rate is relatively high by the pending date of re-election. After being re-elected the incumbent government enacts policies to immediately reduce the inflation rate such that this process repeats itself. ${ }^{23}$ The moderation of the political business cycle under hyperbolic memory discounting is readily visible in Figure 4, wherein the lengths of the model-generated short-run Phillips Curves are significantly shorter compared to the case of exponential discounting. Alternatively stated, the distance traveled in the inflation-unemployment policy space by an incumbent government is relatively smaller over the course of a four-year electoral term. This is due to the fact that voters remember relatively more about the pain of high unemployment over longer discounting delays (the hyperbolic memory discount functions are decaying more slowly than the exponential function), such that the incumbent government cannot get away with nearly as much policy manipulation during the early part of an electoral term.

\subsection{Moderate discounting: Numerical examples and discussion}

When $\rho=0.95$ the implementation of (23) generates the following discounting parameters: $\beta=2.23, \mu=3.68$, and $\eta=2.60$ with $\sigma=0.33$. This is labeled the case of 'moderate

\footnotetext{
${ }^{23}$ As outlined in Nordhaus (1975), the ability to immediately reduce the inflation rate (thereby raising the unemployment rate) follows from the simplifying assumption in the vintage model that the incumbent government has instantaneous control over policy instruments and economic outcomes. The introduction of lags between the implementation of policies and outcomes would serve to smooth this process.
} 
discounting'. The memory discount functions are depicted in Figure 5 for these parameter values. Again, a retrospective voter recalls less during the year or so that immediately precedes an election if the voter hyperbolically discounts past outcomes, relative to an otherwise identical voter who exponentially discounts the past. Yet, over longer retrospective delays, for example between two to four years preceding an election, a voter remembers more under hyperbolic discounting than compared to exponential discounting. Recall that this again reflects Jost's Second Law of Forgetting.

Figure 6 depicts the time paths of the predicted unemployment rate over the course of one electoral term. Remember that cyclical fluctuations exist over the span of multiple electoral terms in this framework. It can be seen in Figure 6 that the incumbent government keeps the economy well below full employment (the model-generated natural rate) for most of a term in office, especially for the case of exponential discounting. But what is most apparent in Figure 6 is the amplitude of the predicted unemployment rate is 25.7 percentage points with exponential discounting, while the peak-to-trough amplitudes are 5.7 percentage points, 4.0 percentage points, and 2.9 percentage points for the standard hyperbolic, hyperbolic-log, and hyperbolicpower forms respectively. The predicted amplitudes corresponding to the alternative hyperbolic functions are reasonable from an empirical perspective. But the amplitude corresponding to the exponential discount function is counterfactual from the perspective that the model economy experiences fluctuations in the unemployment rate at an amplitude that is greater than what was experienced during the US Great Depression, but at a frequency in the model of every four years across electoral cycles!

Figure 7 depicts the time paths of the inflation rate. The average rates of inflation under hyperbolic discounting are roughly in line with what has been experienced in the US over the last several decades. But this is for expositional purposes only. Indeed, it is important to remember that the level of the inflation rate is an artifact of the calibration procedure, which normalizes $\pi_{p}^{*}(0)=0.03$ for the case of hyperbolic-power discounting by searching over numerical values for the initial condition on inflation expectations, $\varepsilon(0)$. Any other level can be easily achieved by using alternative targets to calibrate $\varepsilon(0)$. What is of real importance are the trough-to-peak amplitudes of the inflation rate: amplitudes of 1.6 to 2.9 percentage points corresponding to the alternative cases of hyperbolic discounting are perfectly plausible in advanced economies, yet the amplitude is counterfactual for the case of exponential discounting since most advanced economies do not experience cyclical fluctuations or swings in the inflation rate on the order of 13.7 percentage points every four years.

The model-generated short-run Phillips Curves and the model-generated long-run Phillips Curve are all depicted in Figure 8 for the case of 'moderate discounting'. Recall that the level of the inflation rate is an artifact of the calibration procedure, meaning that all of the curves 
can be shifted easily in the vertical space with alternative inflation targets. Also recall that the incumbent government in the model starts a new electoral term at the most south-easterly point on a short-run Phillips Curve, where the unemployment rate is relatively high but the inflation rate is relatively low. The incumbent government moves the economy up a shortrun Phillips Curve in the north-westerly direction over the course of an electoral term, and it is readily apparent that the distance traveled in the inflation-unemployment policy space is counterfactual with exponential discounting but empirically reasonable under the hyperbolic discounting cases.

\section{$3.4 \quad H i g h$ discounting: Numerical examples and discussion}

Recall that for a value of $\rho=1.35,(23)$ produces the following discount function parameters: $\beta=3.77, \mu=5.98$, and $\eta=4.04$ with $\sigma=0.33$. A value of $\rho=1.35$ is nine percentage points less than the upper bound of empirical estimates for the exponential memory discount rate, yet this parameterization is selected as the 'high discounting' case because it is more than sufficient to reinforce the main point of this paper. Moreover, the predicted amplitude of the unemployment rate under exponential discounting exceeds 100 percentage points at higher discount rates, which is not admissible in the solution technique to the dynamic optimization problem. The alternative memory discount functions are depicted in Figure 9.

In Figure 10 note the grossly counterfactual amplitude of the predicted unemployment rate under exponential memory discounting - the peak-to-trough amplitude is 91.4 percentage points, meaning that the unemployment rate fluctuates between 95.4 percent and 4 percent ever four years! Yet, the amplitudes of the predicted unemployment rate under hyperbolic discounting range between 2.9 percentage points and 6.6 percentage points across the various hyperbolic forms, which is consistent with the US historical experience for the most part. This reveals that the predicted amplitudes of the unemployment rate under hyperbolic discounting are quite robust to the degree of discounting! Figures 11 and 12 depict the time path of the inflation rate and the Phillips Curves respectively. Recall that the level of the inflation rate in these figures is a by-product of the calibration procedure, and what matters most are the sizes of the relative amplitudes across alternative discount functions. These figures reinforce the fact that hyperbolic memory discounting delivers empirical predictions concerning the amplitude of the predicted business cycle that are in line with real-world evidence, whereas an amplitude of 50 percentage points in the inflation rate under exponential discounting is yet again counterfactual. 


\section{Concluding remarks}

Beginning with the findings of Ebbinghaus (1885) and Jost (1897), a large body of research in the field of psychology documents that individuals discount their memories hyperbolically. This behavioral phenomenon has come to be recognized as Jost's Second Law of Forgetting. Given that this research has not received much attention (to the best of my knowledge) in the economics literature to date, the objective of this paper is to demonstrate how incorporating hyperbolic memory discounting into a seminal political economy model can affect its main predictions. I focus on the vintage political business cycle model of Nordhaus (1975) because its setup, motivating assumptions, and baseline predictions are generally well-known.

A key assumption in the original Nordhaus (1975) framework is that voters exponentially discount their memories about the pain of inflation and unemployment. I find that replacing exponential memory discounting with hyperbolic discounting affects the predictions in a significant way. Namely, I find both analytically and numerically that the amplitude of the predicted business cycle is moderated in both the inflation and the unemployment dimensions. This results from the fact that it is not nearly as easy for an opportunistic incumbent government to exploit retrospective voters during the early part of an electoral term if such voters remember relatively more about economic outcomes in that part of the term under hyperbolic discounting relative to exponential memory discounting. A significantly moderated amplitude of the predicted political business cycle might be an underlying reason for the difficulty that many empirical studies have faced in attempting to detect the existence of opportunistic political business cycles in the data.

The findings presented in this paper highlight the potential role and impact that hyperbolic memory discounting can have on predicted economic outcomes. There are other strands of research on political business cycles that I think would be interesting to re-visit with hyperbolic discounting, such as models with political-partisan competition (e.g., Hibbs 1977, 1992; Alesina and Rosenthal 1995) and political budget cycles (e.g., Aidt, Veiga, and Veiga 2011; Efthyvoulou 2012; Klomp and de Haan 2013; Foremny and Riedel 2014; Shelton 2014). It would also be very interesting to re-visit the literature on rational (opportunistic and partisan) political business cycles (e.g., Alesina 1987; Rogoff 1990; Sieg 1997, 2001, 2006; Aidt, Veiga, and Veiga 2011) and explore how the predictions of such models might change under the alternative assumption of forward-looking hyperbolic discounting à la Strotz (1956) and Laibson (1997, 1998). Lastly, it would be of interest to see how the predicted political business cycle and the timing of elections might be affected by hyperbolic discounting if the date of re-election is a choice variable of the incumbent (Chappell and Peel 1979; Lächler 1982). I believe that studying these possibilities deserves more attention, and I have therefore placed these on the agenda for future research. 


\section{Acknowledgments}

I thank Shantanu Bagchi, Frank Caliendo, Mike Clagg, Chris Fawson, Jim Feigenbaum, Vincenzo Galasso, Gerhard Glomm, Nick Guo, Hyeon Park, Bill Shughart, Randy Simmons, Diana Thomas, Michael Thomas, Christoph Trebesch, and seminar participants at the CESifo Venice Summer Institute on Behavioural Political Economy (July 2014; Venice, Italy), the Bay Area Behavioral and Experimental Economics Workshop (May 2014; Stanford University), the Center for Economic Studies (CES) at Ludwig-Maximilians-Universität München, and at the SABE/IAREP/ICABEEP Biennial Conference (July 2013; Atlanta, Georgia) for providing helpful comments. I acknowledge and thank two anonymous reviewers and Heinrich Ursprung for suggestions that have improved this manuscript during the review process. An early version of this manuscript was circulated under the title, 'Nordhaus Meets Ebbinghaus and Jost in the Political Business Cycle Model'.

\section{References}

Agliari, A., Chiarella, C., Gardini, L., 2006. A re-evaluation of adaptive expectations in light of global nonlinear dynamic analysis. Journal of Economic Behavior and Organization 60, $526-552$.

Aidt, T.S., Veiga, F.J., Veiga, L.G., 2011. Election results and opportunistic policies: A new test of the rational political business cycle model. Public Choice 148, 21-44.

Ainslie, G., 1975. Specious reward: A behavioral theory of impulsiveness and impulse control. Psychological Bulletin 82, 463-496.

Alesina, A., 1987. Macroeconomic policy in a two-party system as a repeated game. Quarterly Journal of Economics 102, 651-678.

Alesina, A., Rosenthal, H., 1995. Partisan Politics, Divided Government, and the Economy. Cambridge University Press, New York.

Alin, L.H., 1997. The memory laws of Jost. Göteborg Psychological Reports 27, 1-21.

Anderson, C.J., 2000. Economic voting and political context: A comparative perspective. Electoral Studies 19, 151-170.

Averell, L., Heathcote, A., 2011. The form of the forgetting curve and the fate of memories. Journal of Mathematical Psychology 55, 25-35.

Basak, G.K., Ghosh, M.K., Mukherjee, D., 2015. A mean-reverting stochastic model for the political business cycle. Working paper, unpublished. Indian Statistical Institute, Kolkata, India.

Brown, G.D.A., Neath, I., Chater, N., 2007. A temporal ratio model of memory. Psychological Review 114, 539-576.

Burmeister, E., Turnovsky, S.J., 1976. The specification of adaptive expectations in continuous time dynamic economic models. Econometrica 44, 879-905. 
Caliendo, F.N., Findley, T.S., 2014. Discount functions and self-control problems. Economics Letters 122, 416-419.

Campbell, J.E., Dettrey, B.J., Yin, H., 2010. The theory of conditional retrospective voting: Does the presidential record matter less in open-seat elections? Journal of Politics 72, 1083-1095.

Chappell, D., Peel, D.A., 1979. On the political theory of the business cycle. Economics Letters $2,327-332$.

Chappell, Jr., H.W., 1983. Presidential popularity and macroeconomic performance: Are voters really so naive? Review of Economics and Statistics 65, 385-392.

Ebbinghaus, H., 1885. Ueber das Gedächtnis. Verlag von Duncker \& Humbolt, Leipzig.

Efthyvoulou, G., 2012. Political budget cycles in the European Union and the impact of political pressures. Public Choice 153, 295-327.

Evans, G.W., Honkapohja, S., 2001. Learning and Expectations in Macroeconomics. Princeton University Press, Princeton.

Fair, R.C., 1978. The effect of economic events on votes for president. Review of Economics and Statistics 60, 159-173.

Fiorina, M.P., 1981. Retrospective Voting in American National Elections. Yale University Press, New Haven.

Foremny, D., Riedel, N., 2014. Business taxes and the electoral cycle. Journal of Public Economics 115, 48-61.

Francis, W.L., Kenny, L.W., Morton, R.B., Schmidt, A.B., 1994. Retrospective voting and political mobility. American Journal of Political Science 38, 999-1024.

García-Sanchez, I.-M., Mordán, N., Cuadrado-Ballesteros, B., 2014. Do electoral cycles affect local financial health? Policy Studies 35, 533-556.

Gordon, R.J., 1997. The time-varying NAIRU and its implications for economic policy. Journal of Economic Perspectives 11, 11-32.

Haller, H.B., Norpoth, H., 1994. Let the good times roll: The economic expectations of U.S. voters. American Journal of Political Science 38, 625-650.

Herrnstein, R.J., 1961. Relative and absolute strength of responses as a function of frequency of reinforcement. Journal of the Experimental Analysis of Behavior 4, 267-272.

Hey, J.D., 1994. Expectations formation: Rational or adaptive or...? Journal of Economic Behavior and Organization 25, 329-349.

Hibbs, Jr., D.A., 1977. Political parties and macroeconomic policies. American Political Science Review 71, 1467-1487.

Hibbs, Jr., D.A., 1987. The American Political Economy: Macroeconomics and Electoral Politics. Harvard University Press, Cambridge.

Hibbs, Jr., D.A., 1992. Partisan theory after fifteen years. European Journal of Political Economy 8, 361-373. 
Hibbs, Jr., D.A., Vasilatos, N., 1981. Economics and politics in France: Economic performance and mass political support for Presidents Pompidou and Giscard d'Estaing. European Journal of Political Research 9, 133-145.

Hibbs, Jr., D.A., Vasilatos, N., 1982. Economic outcomes and political support for British governments among occupational class: A dynamic analysis. American Political Science Review 76, 259-279.

Hibbs, Jr., D.A., Rivers, R.D., Vasilatos, N., 1982. On the demand for economic outcomes: Macroeconomic performance and mass political support in the United States, Great Britain, and Germany. Journal of Politics 44, 426-462.

Hovland, C.I., 1951. Human learning and retention. In: Stevens, S.S. (Ed.), Handbook of Experimental Psychology. John Wiley \& Sons, Inc., New York, pp. 613-689.

Jost, A., 1897. Die Assoziationsfestigkeit in ihrer Abhängigkeit von der Verteilung der Wiederholungen. Zeitschrift fuer Psychologie und Physiologie der Sinnesorgane 14, 436-472.

Kalecki, M., 1943. Political aspects of full employment. Political Quarterly 14, 322-330.

Kiewiet, D.R., Udell, M., 1998. Twenty-five years after Kramer: An assessment of economic retrospective voting based upon improved estimates of income and unemployment. Economics and Politics 10, 219-248.

King, T.B., Morley, J., 2007. In search of the natural rate of unemployment. Journal of Monetary Economics 54, 550-564.

Klomp, J., de Haan, J., 2013. Political budget cycles and election outcomes. Public Choice 157, 245-267.

Lächler, U., 1982. On political business cycles with endogenous election dates. Journal of Public Economics 17, 111-117.

Laibson, D., 1997. Golden eggs and hyperbolic discounting. Quarterly Journal of Economics $112,443-478$.

Laibson, D., 1998. Life-cycle consumption and hyperbolic discount functions. European Economic Review 42, 861-871.

Lanoue, D.J., 1994. Retrospective and prospective voting in presidential-year elections. Political Research Quarterly 47, 193-205.

Lee, J., Nelson, C.R., 2007. Expectation horizon and the Phillips curve: The solution to an empirical puzzle. Journal of Applied Econometrics 22, 161-178.

Mueller, D.C., 2003. Public Choice III. Cambridge University Press, Cambridge UK.

Murakami, M.H., 2008. Paradoxes of democratic accountability: Polarized parties, hard decisions, and no despot to veto. Critical Review: A Journal of Politics and Society 20, 91-113.

Muth, J.F., 1960. Optimal properties of exponentially weighted forecasts. Journal of the American Statistical Association 55, 299-306.

Myerson, J., Green, L., Warusawitharana, M., 2001. Area under the curve as a measure of discounting. Journal of the Experimental Analysis of Behavior 76, 235-243. 
Myerson, J., Green, L., Hanson, J.S., Holt, D.D., Estle, S.J., 2003. Discounting delayed and probabilistic rewards: Processes and traits. Journal of Economic Psychology 24, 619-635.

Myerson, J., Green, L., 2004. A discounting framework for choice with delayed and probabilistic rewards. Psychological Bulletin 130, 769-792.

Nadeau, R., Lewis-Beck, M.S., 2001. National economic voting in U.S. presidential elections. Journal of Politics 63, 159-181.

Nordhaus, W.D., 1975. The political business cycle. Review of Economic Studies 42, 169-190.

Rachlin, H., 2006. Notes on discounting. Journal of the Experimental Analysis of Behavior 85, 425-435.

Rachlin, H., Green, L., 1972. Commitment, choice and self control. Journal of the Experimental Analysis of Behavior 17, 15-22.

Rogoff, K., 1990. Equilibrium political budget cycles. American Economic Review 80, 21-36.

Rubin, D.C., Wenzel, A.E., 1996. One hundred years of forgetting: A quantitative description of retention. Psychological Review 103, 734-760.

Salemi, M.K., 1999. Estimating the natural rate of unemployment and testing the natural rate hypothesis. Journal of Applied Econometrics 14, 1-25.

Sargent, T.J., 1999. The Conquest of American Inflation. Princeton University Press, Princeton.

Shepherd, B., 2012. When are adaptive expectations rational? A generalization. Economics Letters 115, 4-6.

Shelton, C.A., 2014. Legislative budget cycles. Public Choice 159, 251-275.

Sieg, G., 1997. A model of partisan central banks and opportunistic political business cycles. European Journal of Political Economy 13, 503-516.

Sieg, G., 2001. A political business cycle with boundedly rational agents. European Journal of Political Economy 17, 39-52.

Sieg, G., 2006. A model of an opportunistic-partisan political business cycle. Scottish Journal of Political Economy 53, 242-252.

Snowdon, B., 1997. Politics and the business cycle. Political Quarterly 68, 255-265.

Söderlund, P., 2008. Retrospective voting and electoral volatility: A Nordic perspective. Scandinavian Political Studies 31, 217-240.

Sorge, M.M., 2013. Generalized adaptive expectations revisited. Economics Letters 120, 203205.

Staiger, D.O., Stock, J.H., Watson, M.W., 1997. How precise are estimates of the natural rate of unemployment? In: Romer, C.D., Romer, D.H. (Eds.), Reducing Inflation: Motivation and Strategy. University of Chicago Press, Chicago, pp. 195-246.

Strotz, R.H., 1956. Myopia and inconsistency in dynamic utility maximization. Review of Economic Studies 23, 165-180.

Suzuki, M., 1991. The rationality of economic voting and the macroeconomic regime. American Journal of Political Science 35, 624-642. 
Vásquez-Ruíz, H.A., Rivas, R., Díaz, R., 2014. Do politics determine policy? Evidence on the political-economic business cycle in the Dominican Republic. Working paper, unpublished. Central Bank of the Dominican Republic, Santo Domingo, Dominican Republic.

Williams, K.C., 1994. Sequential elections and retrospective voting: Some laboratory experiments. Journal of Theoretical Politics 6, 239-255.

Wixted, J.T., Ebbesen, E.B., 1991. On the form of forgetting. Psychological Science 2, 409-415.

Wixted, J.T., 2004. The psychology and neuroscience of forgetting. Annual Review of Psychology 55, 235-269.

Yi, R., Gatchalian, K.M., Bickel, W.K., 2006. Discounting of past outcomes. Experimental and Clinical Psychopharmacology 14, 311-317.

Yi, R., Landes, R.D., Bickel, W.K., 2009. Novel models of intertemporal valuation: Past and future outcomes. Journal of Neuroscience, Psychology, and Economics 2, 102-111. 


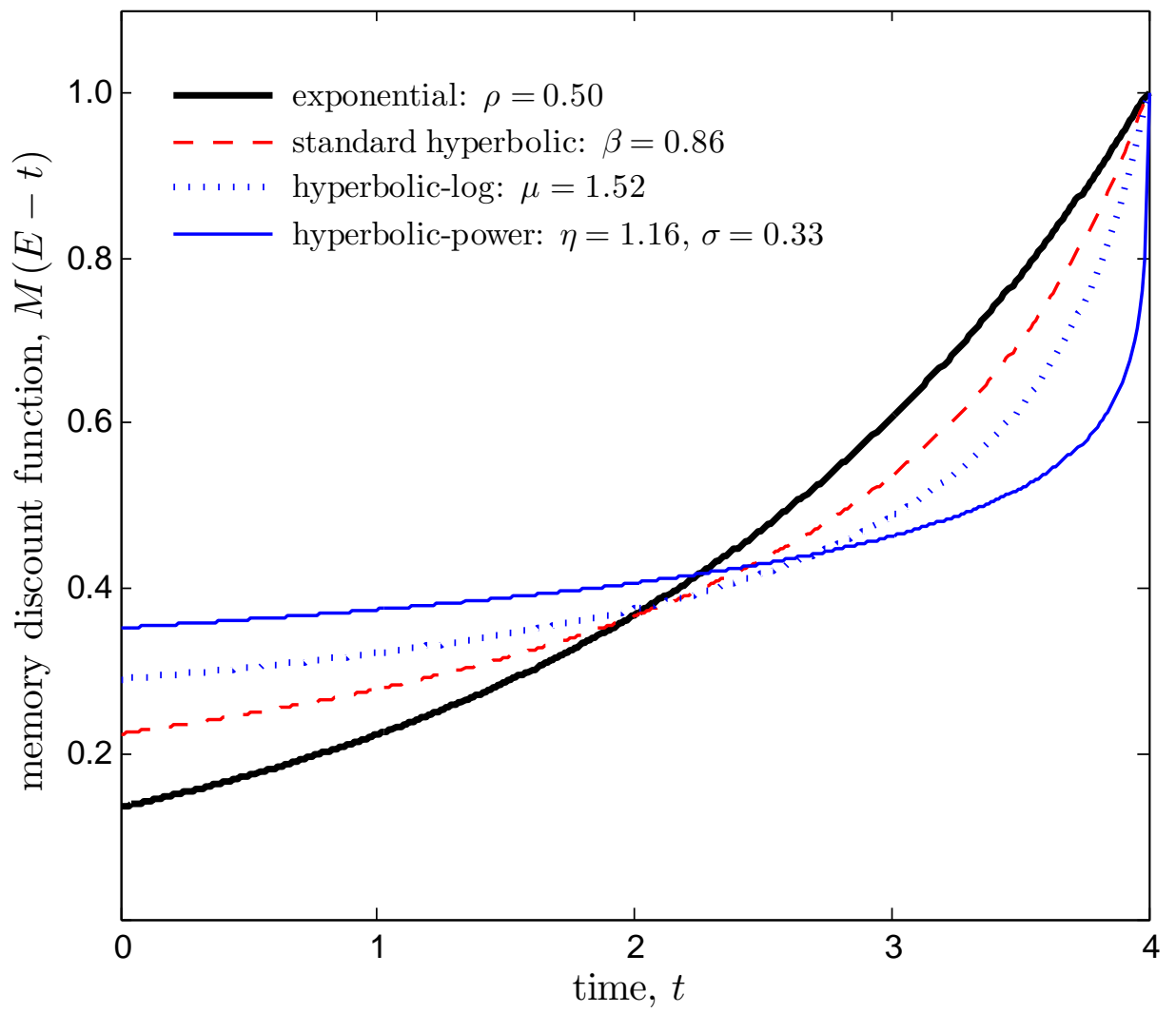

Figure 1. Memory discount functions, low discounting

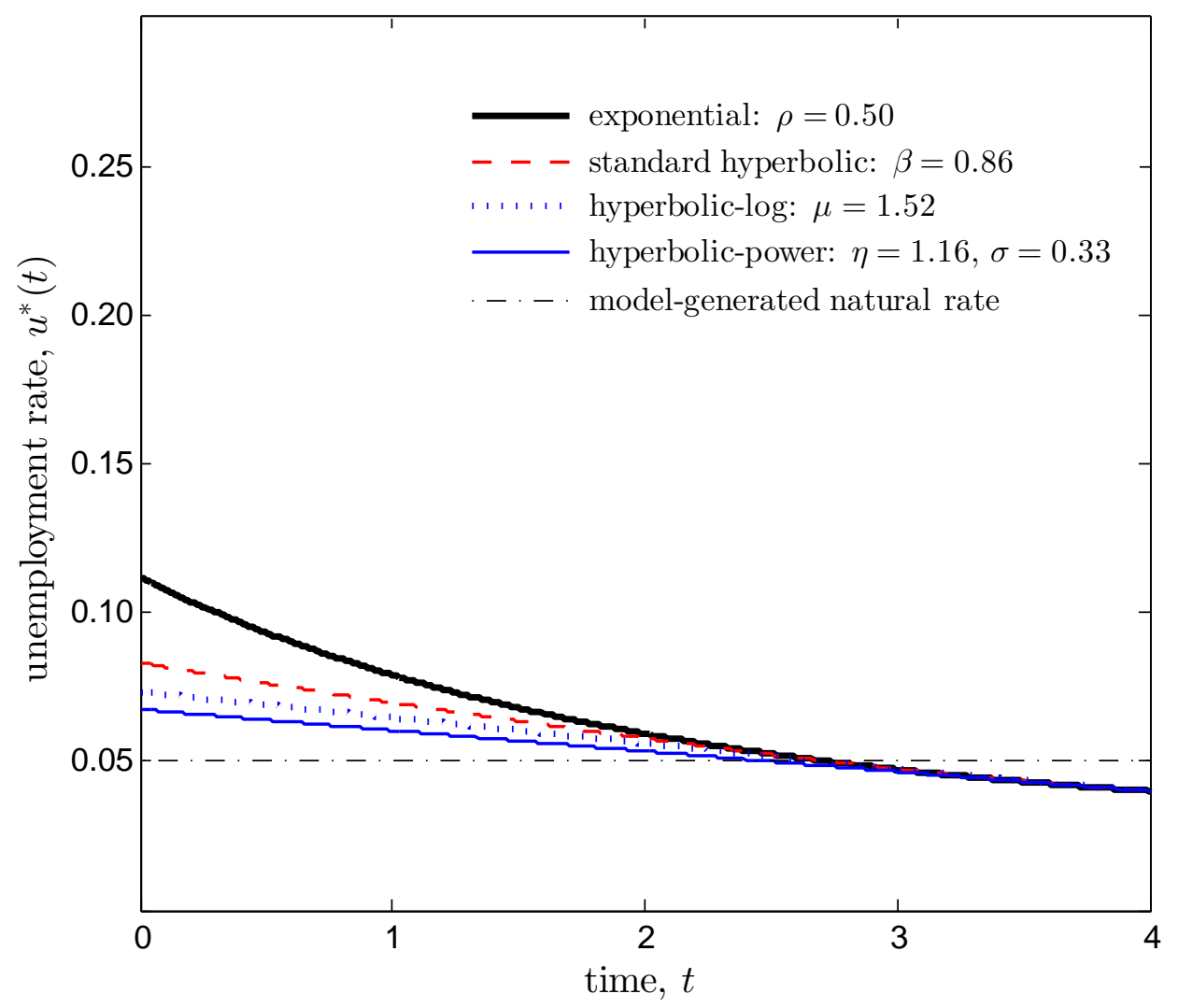

Figure 2. Unemployment rate, low discounting 


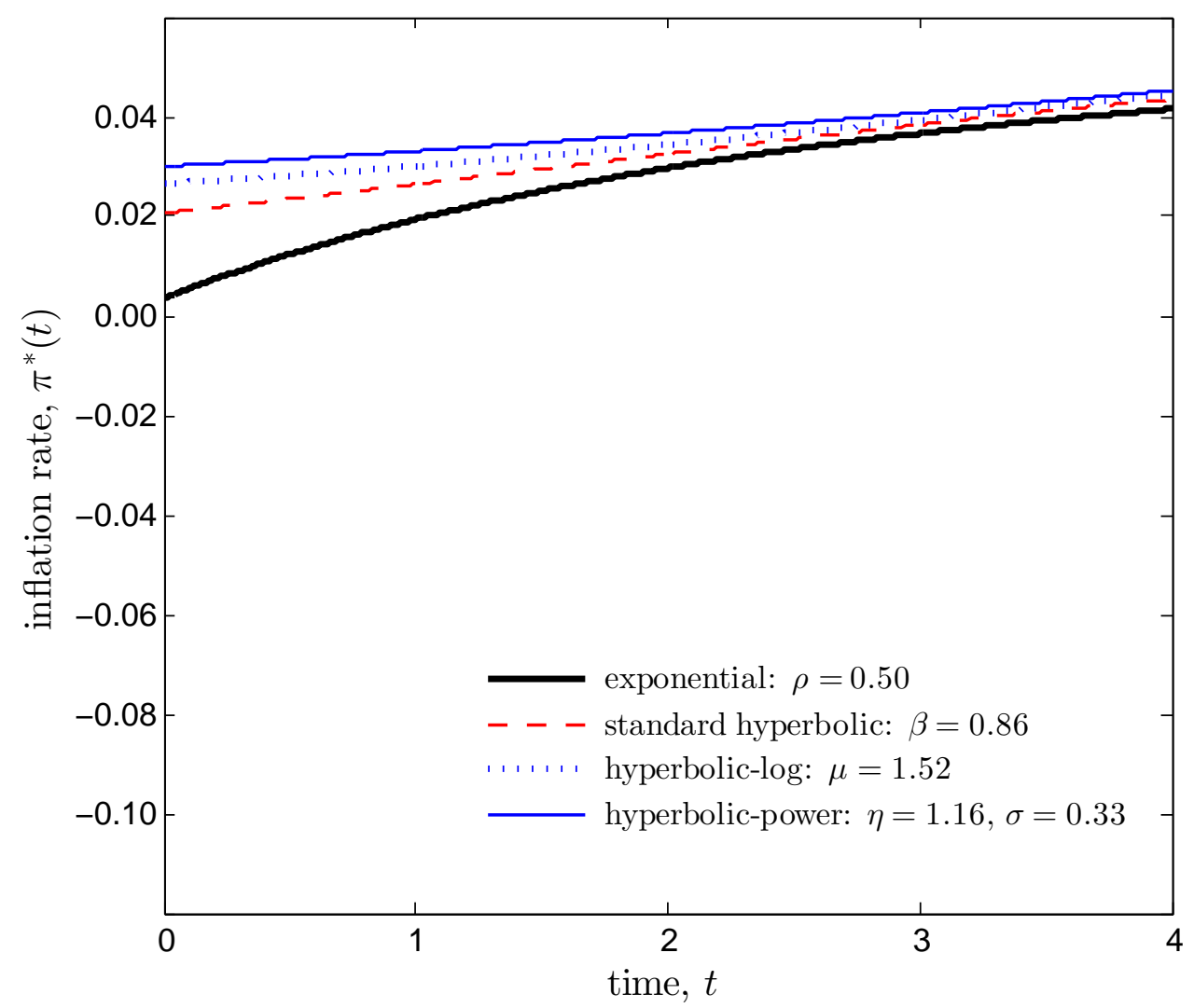

Figure 3. Inflation rate, low discounting

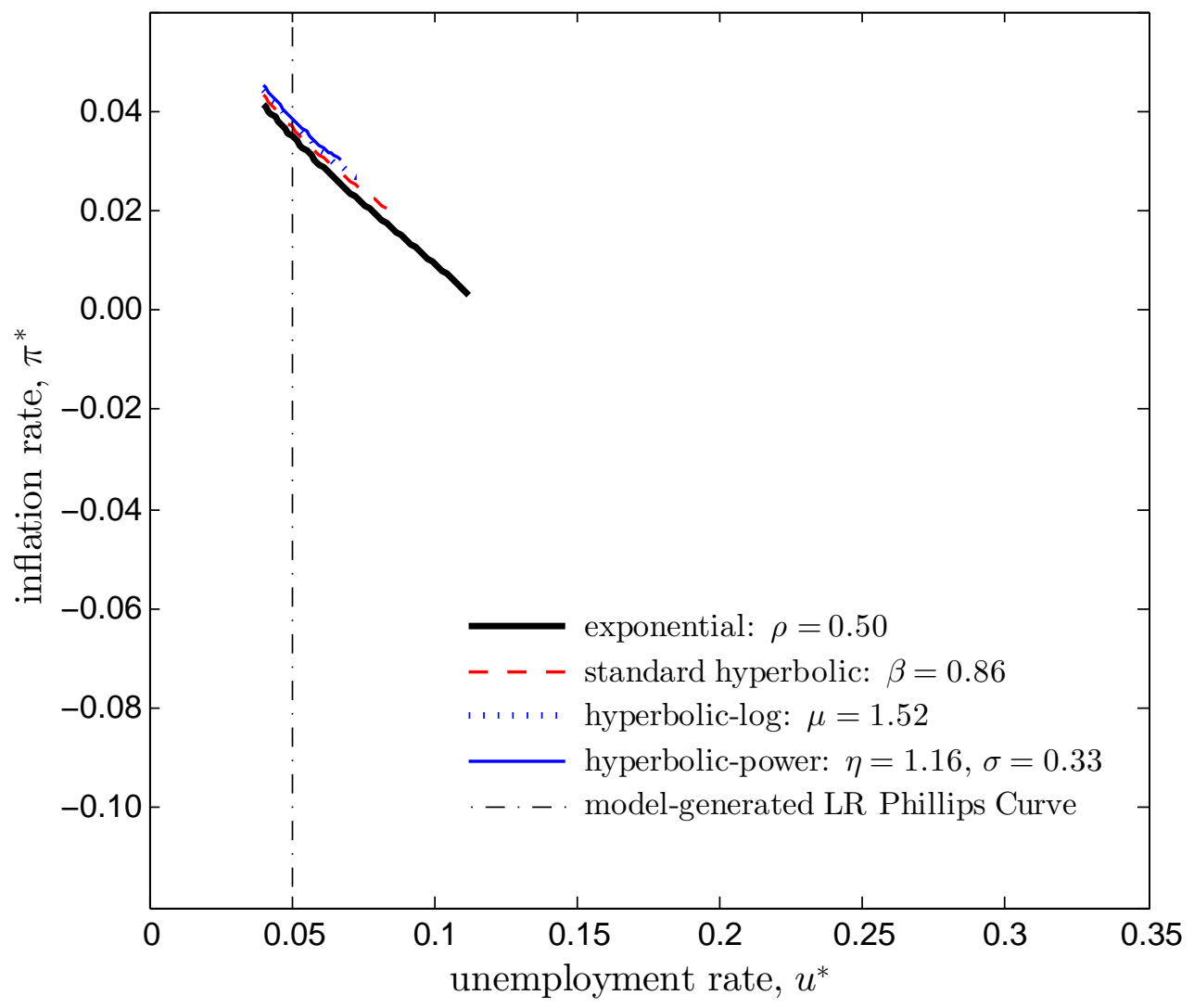

Figure 4. Model-generated SR Phillips Curves, low discounting 


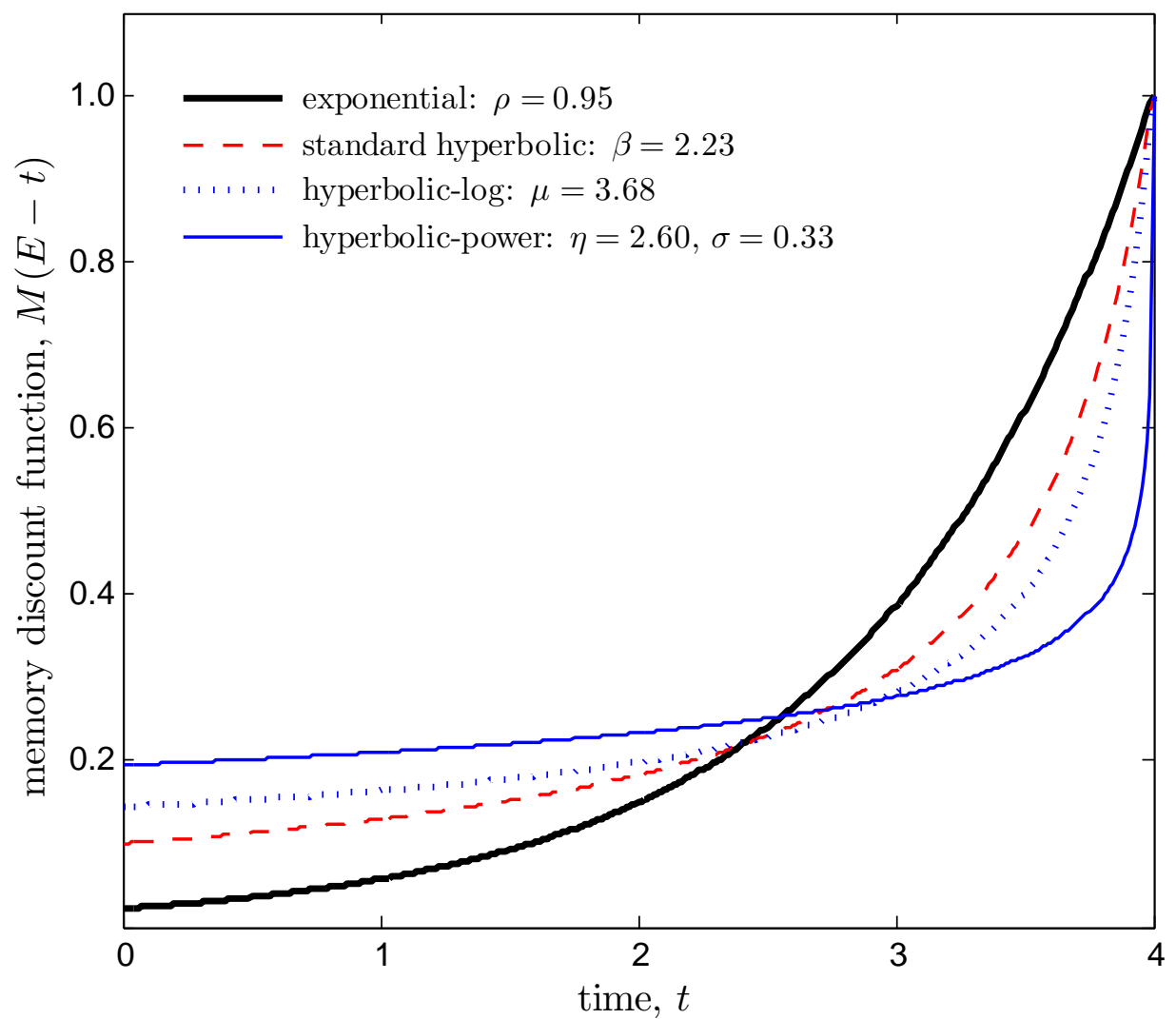

Figure 5. Memory discount functions, moderate discounting

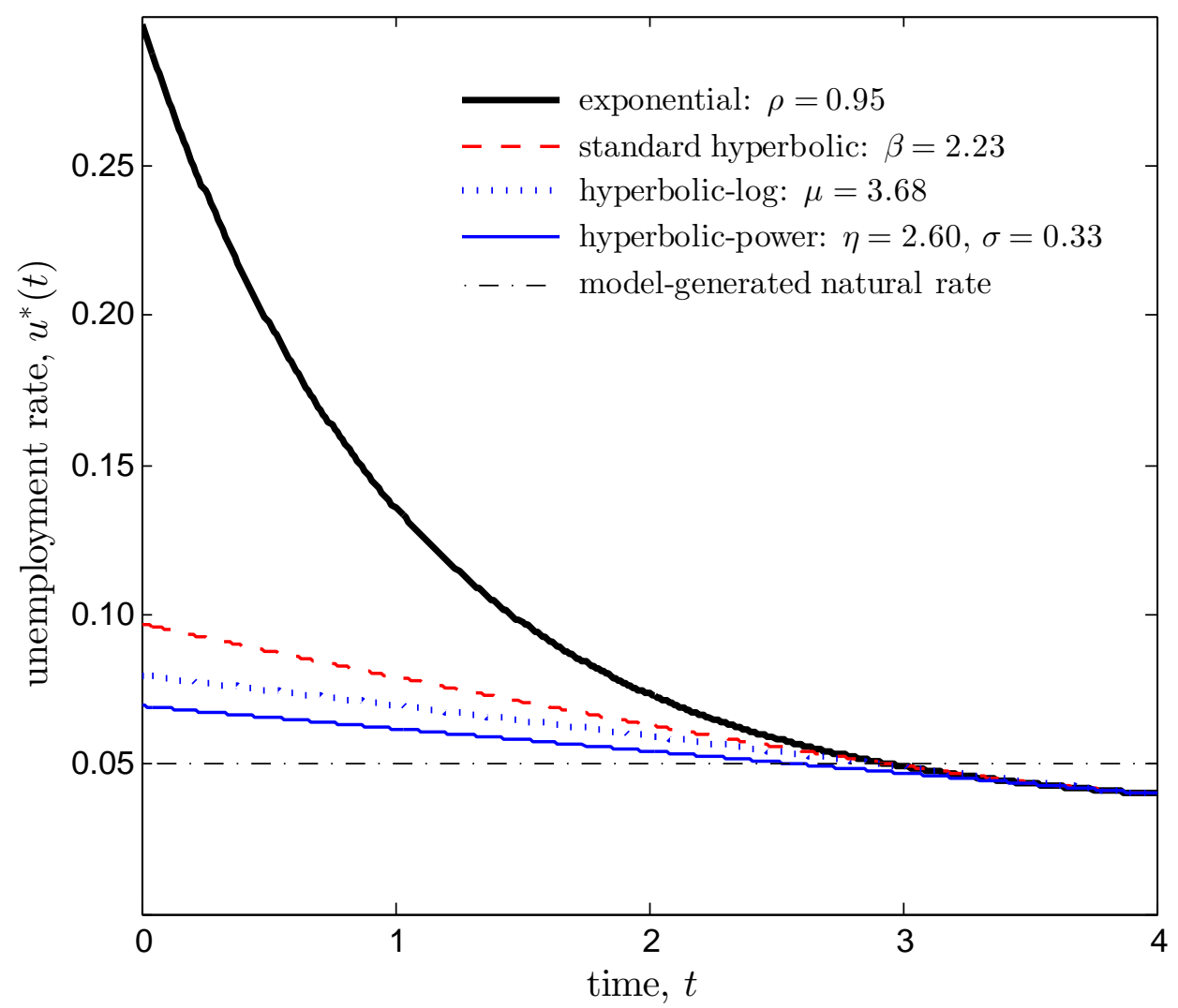

Figure 6. Unemployment rate, moderate discounting 


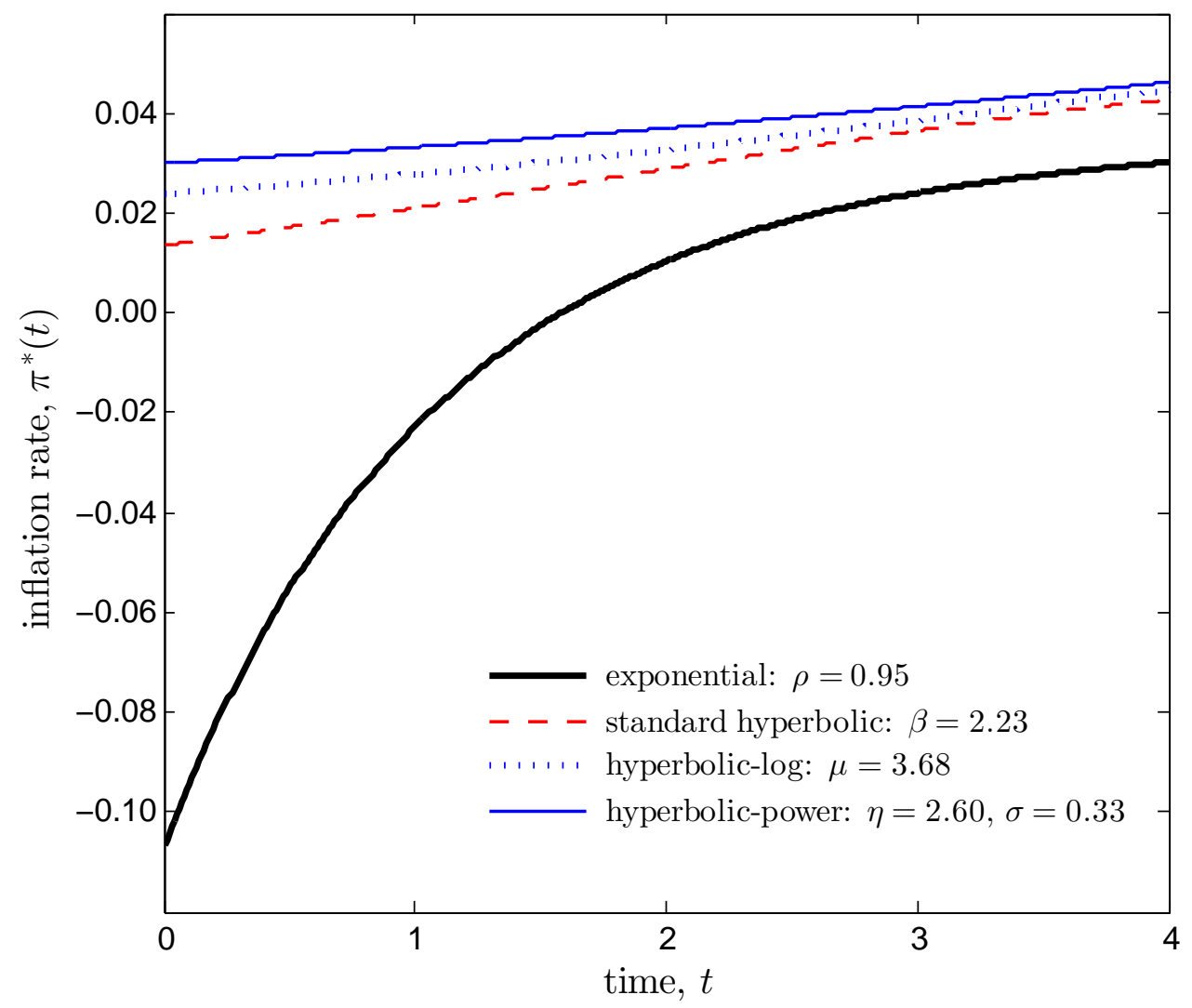

Fig ure 7 . Inflation rate, moderate discounting

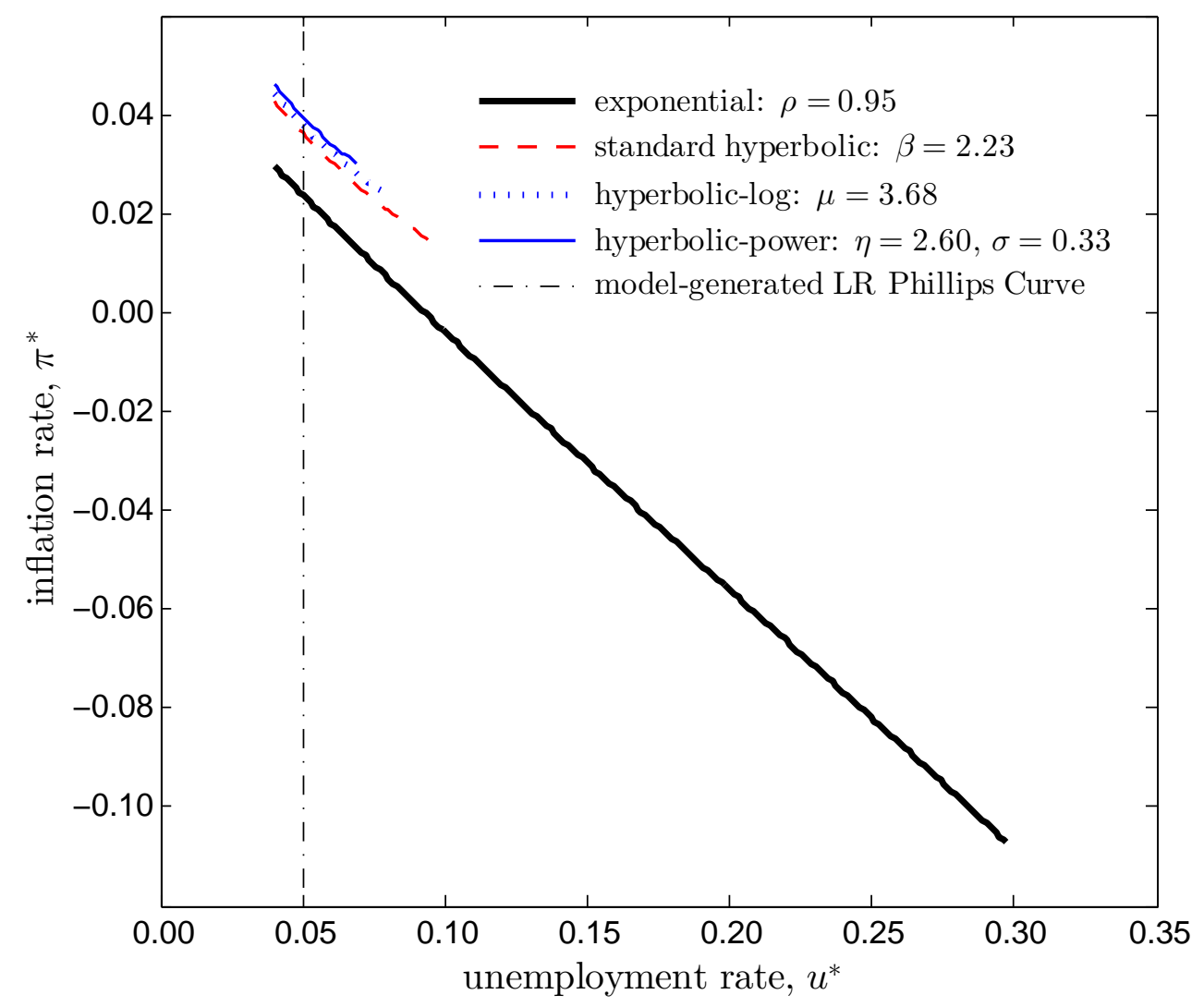

Figure 8. Model-generated SR Phillips Curves, moderate discounting 


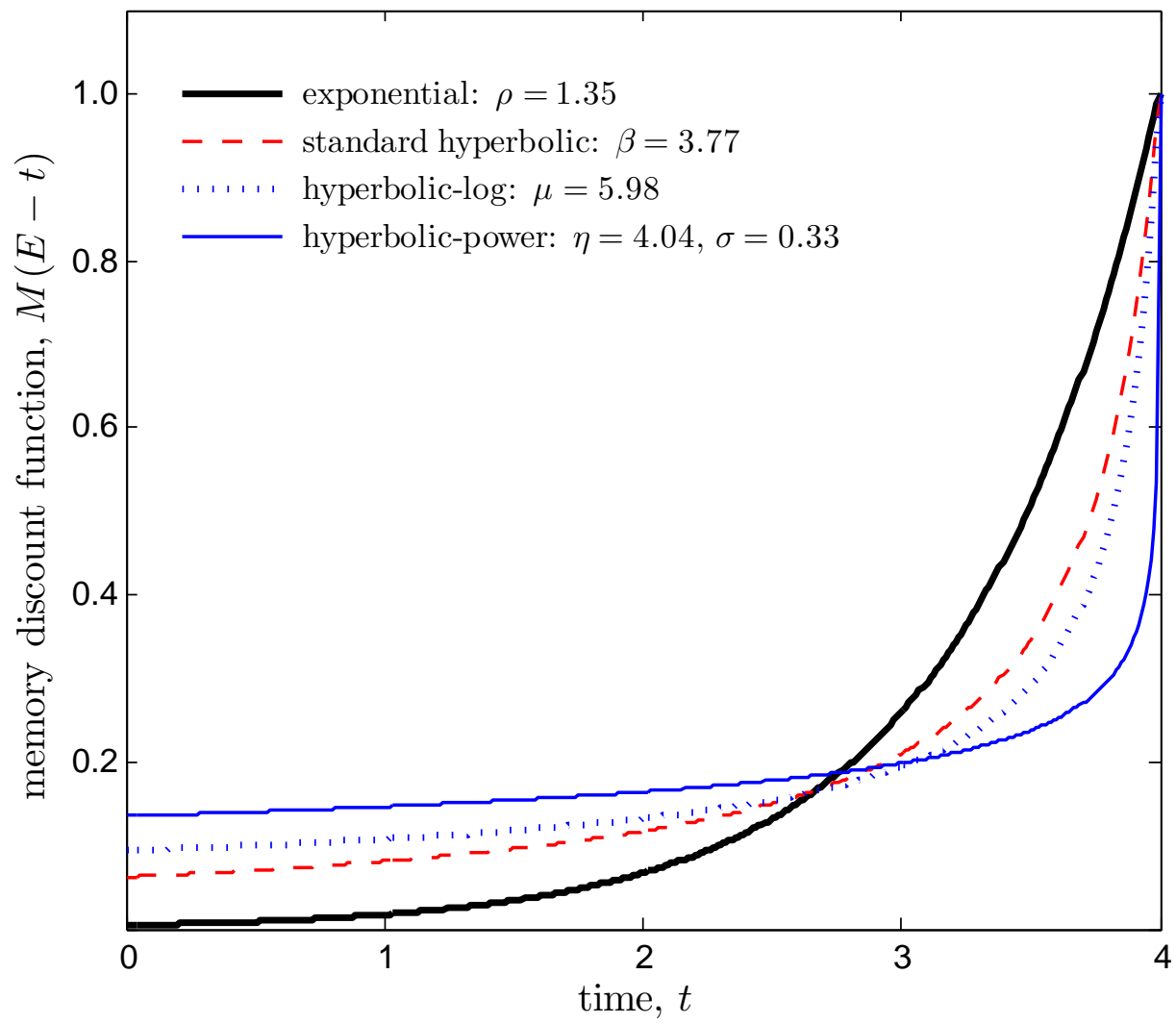

Figure 9. Memory discount functions, high discounting

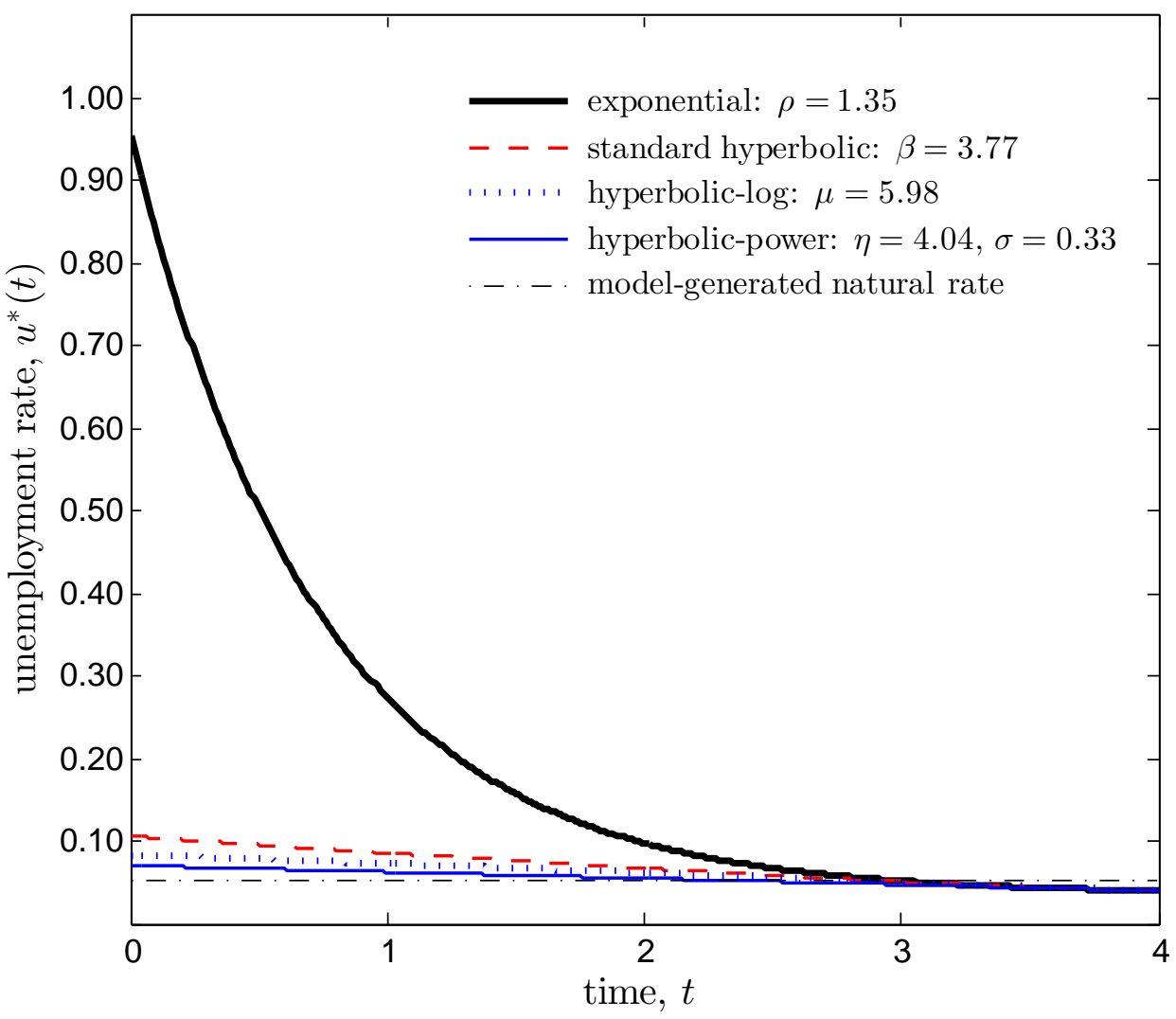

Figure 10. Unemployment rate, high discounting 


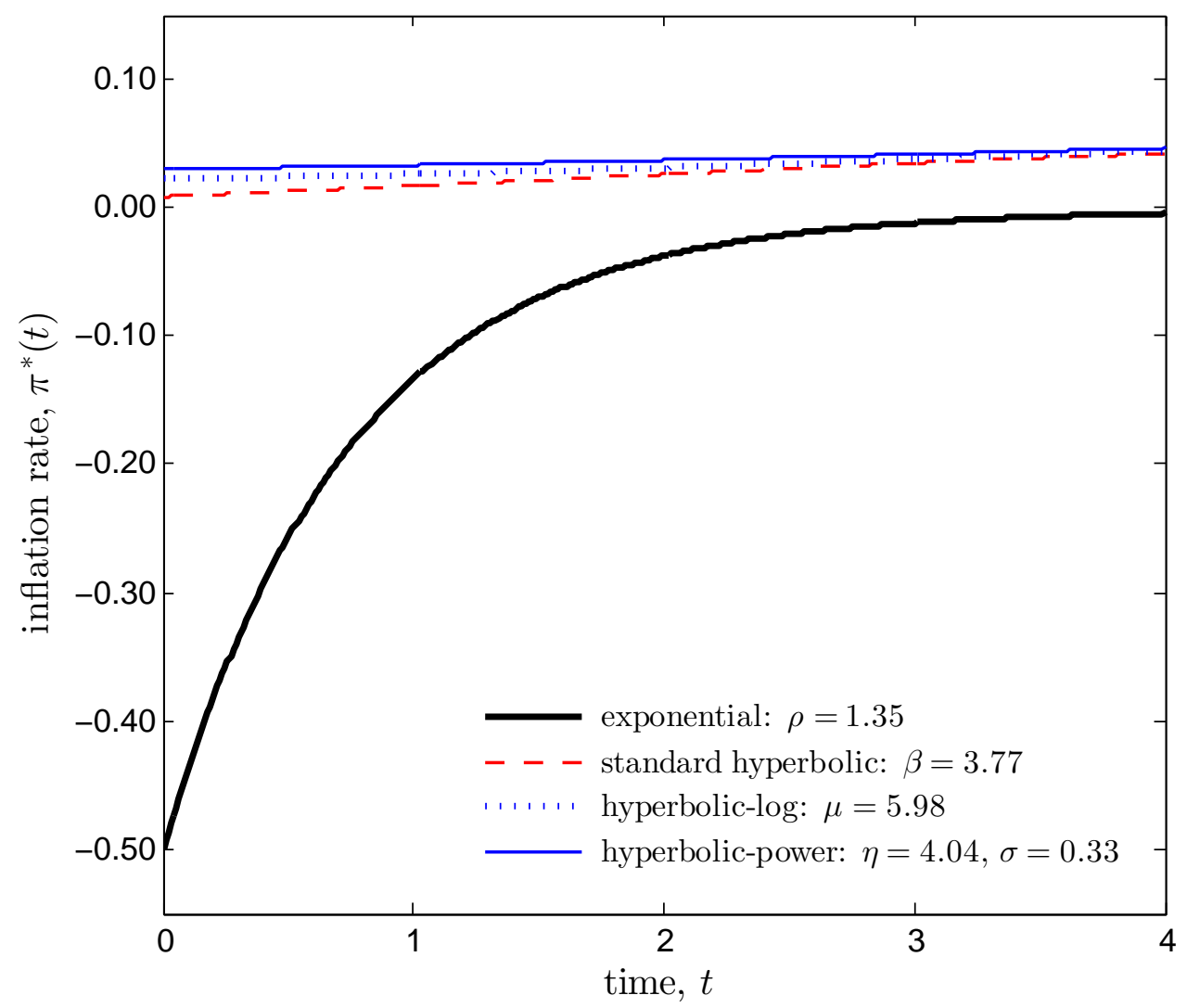

Figure 11. Inflation rate, high discounting

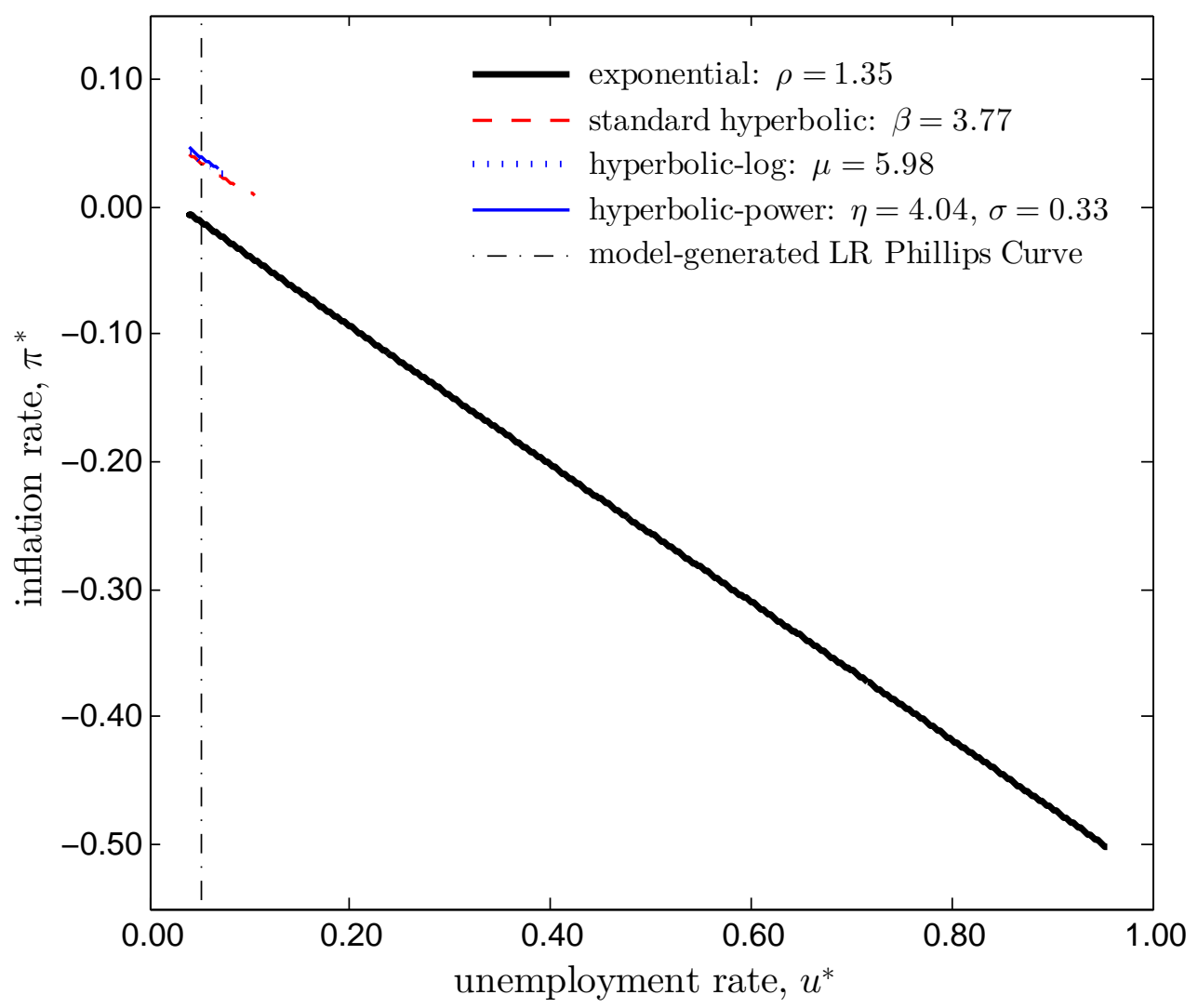

Figure 12. Model-generated SR Phillips Curves, high discounting 